\title{
Extraction and precipitation particle coating using supercritical $\mathrm{CO}_{2}$
}

\author{
Yulu Wang ${ }^{\mathrm{a}}$, Dongguang Wei ${ }^{\mathrm{a}}$, Rajesh Dave ${ }^{\mathrm{a}}$, Robert Pfeffer ${ }^{\mathrm{a}, *}$, Martial Sauceau ${ }^{\mathrm{b}}$, \\ Jean-Jacques Letourneau ${ }^{b}$, Jacques Fages ${ }^{b}$ \\ ${ }^{a}$ Department of Chemical Engineering, Chemistry and Environmental Science, New Jersey Institute of Technology, University Heights, \\ Neward, NJ 07102-1982, USA \\ ${ }^{\mathrm{b}}$ Ecole Des Mines D'Albi, Laboratoire de Génie des Procédés des Solides Divisés, UMR-CNRS 2392, 81013 Albi, France
}

\begin{abstract}
A modified RESS process for particle coating with a solution of polymer in supercritical $\mathrm{CO}_{2}$ was studied in this research. This technique involves extracting the polymer with supercritical $\mathrm{CO}_{2}$, with or without a cosolvent in an extraction vessel, and then precipitating the polymer onto the surface of host particles in a second precipitation vessel by adjusting the pressure and temperature inside the precipitator to lower its solubility. The research was performed using a pilot-scale supercritical apparatus, glass beads as host particles and two different polymers as coating materials. Experiments showed that the coating of glass beads with polyvinyl chloride-co-vinyl acetate (PVCVA) and hydroxypropyl cellulose (HPC) was successfully achieved. Scanning electron microscopy (SEM), energy dispersive X-ray spectrometry (EDS), energy dispersive X-ray mapping and thermogravimetric analysis (TGA) were used to characterize the coatings obtained. The results indicate that the process of particle coating with supercritical solution is a promising environmentally friendly, alternative coating method with little or no organic solvents required.
\end{abstract}

Keywords: Supercritical $\mathrm{CO}_{2}$; Particle coating; Polymer; Cosolvent; RESS

\section{Introduction}

Particle coating involves the application of another material onto the surface of individual particles to modify their surface properties, such as flowability, wettability, time release, flavor, taste, etc. Conventional particle coating processes usually employ wet chemistry or solutions of the coating material, requiring the use of large quantities of organic solvents, surfactants and other chemicals. In general, these processes are environmentally unfriendly and can lead to the emissions of volatile organic compounds (VOCs) and other waste streams. Dry particle coating [1] is a good alternative because no organic solvents are employed, not even water. Moreover, no drying is needed; thus, these processes save energy. Coating is achieved through mechanical forces between host and much smaller guest particles, which are attached to the surface of the host particles. But it is often difficult to control the film structure on the surface of the host particles, such as the film thickness, uniformity,

\footnotetext{
* Corresponding author. Tel.: +1-973-642-7496; fax: +1-973-642-7496 E-mail address: pfeffer@njit.edu (R. Pfeffer).
}

texture and robustness of the coating. Furthermore, some bioactive particles, for example, proteins and peptides, may lose much of their bioactivity due to the high shear and compressive forces employed and the local increase in temperature produced in dry coating processes.

A supercritical fluid (SCF) is a fluid above its critical temperature $\left(T_{\mathrm{c}}\right)$ and critical pressure $\left(P_{\mathrm{c}}\right)$ and has many advantages over conventional fluids. Its gas-like viscosity and high diffusivity is advantageous for mass transfer applications. Its density and related solvent strength can be tuned by controlling the temperature and pressure. Carbon dioxide is the most widely used SCF because of its low critical temperature $\left(31.1{ }^{\circ} \mathrm{C}\right)$ and mild critical pressure (73.8 bars), nontoxicity, nonflammability and low price. During the past two decades, SCF technologies have developed very rapidly. Originally, SCF processes were developed and widely used in extraction and separation because of the good solvent properties of SCFs. Since the mid-1980s, however, particle synthesis and engineering using supercritical $\mathrm{CO}_{2}$ has emerged as a fast-growing field. The rapid expansion of supercritical solution (RESS) process to form fine particles was first suggested by Krukonis [2]. In RESS [3-6], a SCF solution is expanded through a 
Table 1

Polymer properties

\begin{tabular}{llll}
\hline Polymers & $\begin{array}{l}\text { Molecular } \\
\text { weight }\end{array}$ & $\begin{array}{l}\text { Glass transition } \\
\text { temperature } \\
\left(T_{\mathrm{g}},{ }^{\circ} \mathrm{C}\right)\end{array}$ & Content (\% wt.) \\
\hline PVCVA & $27,000\left(\mathrm{Mn}^{\mathrm{a}}\right)$ & 72 & $\begin{array}{l}86 \% \text { polyvinyl } \\
\text { chloride } \\
100 \%\end{array}$ \\
HPC & 100,000 & - & 100
\end{tabular}

a Mn, number average molecular weight.

nozzle or capillary tube, resulting in a very high pressure drop and a high degree of supersaturation. The solute will nucleate and grow, forming very small particles.

Another technique, using a SCF as an antisolvent, for particle engineering has been developed in a variety of forms. These include the supercritical antisolvent (SAS) technique [7-12], gas antisolvent (GAS) [13-17], aerosol solvent extraction system (ASES) [18-21] and solution enhanced dispersion by SCFs (SEDS) [22,23]. However, all of these techniques and the investigators who used them, focused on single component powder formation.

Multicomponent particle formation, such as particle composites or encapsulation of particles with polymer using $\mathrm{SCFs}$, is of great interest for controlled drug delivery, food, agriculture, and cosmetics applications. Recently, Kim et al. [24] reported the microencapsulation of naproxen with polyL-lactic acid (PLA) using RESS. Naproxen and PLA were packed in an extraction unit and extracted with supercritical $\mathrm{CO}_{2}$. The supercritical solution was then expanded through a capillary tube. Composite particles with a naproxen core encapsulated by a polymer coating were produced. Microparticles and agglomerates were observed as the dominant morphology. Mishima et al. [25] investigated the microencapsulation of proteins with polyethylene glycol (PEG) by RESS. In this research, ethanol (about 38.5 wt.\%) was
Table 2

Experimental conditions

\begin{tabular}{llll}
\hline Coating experiments & PVCVA-1 & PVCVA-2 & HPC \\
\hline Size of glass beads $(\mu \mathrm{m})$ & 315 & 500 & 500 \\
Weight of glass beads $(\mathrm{g})$ & 3.1558 & 2.8224 & 4.0268 \\
Weight of polymer $(\mathrm{g})$ & 1.1789 & 0.5036 & 0.9336 \\
Extraction $T$ and $P\left({ }^{\circ} \mathrm{C}\right.$, bars $)$ & 80,127 & 84,130 & 80,106 \\
Precipitation $T$ and $P\left({ }^{\circ} \mathrm{C}\right.$, bars $)$ & 30,118 & 48,115 & 30,80 \\
Running time $(\mathrm{min})$ & 25 & 12 & 20 \\
Flushing time $(\mathrm{min})$ & 10 & 0 & 10 \\
Flow rate of $\mathrm{CO}_{2}(\mathrm{~kg} / \mathrm{h})$ & $15-20$ & $15-20$ & $15-20$ \\
Cosolvent used & Acetone & None & Acetone \\
Flow rate of cosolvent $(\mathrm{ml} / \mathrm{min})$ & 2.0 & 0 & 2.0 \\
\hline
\end{tabular}

employed as a cosolvent to enhance the solubility of PEG in supercritical $\mathrm{CO}_{2}$ even though ethanol, by itself, is a nonsolvent for PEG. The results indicated that lipase and lysozyme particles were completely encapsulated by PEG without agglomeration.

Tsutsumi et al. [26] used a combination of RESS with fluidized bed technology. Catalyst particles in a fluidized bed were fluidized by air, and a solution of paraffin in supercritical $\mathrm{CO}_{2}$ was sprayed into the bed through a nozzle. Coating material was directly deposited onto the surface of the catalyst particles with no binder or solvent involved, resulting in no significant agglomeration. A more recent study of particle coating granulation using the RESS process in a fluidized bed was carried out by Wang et al. [27]. However, the main drawback for the RESS technique is that SCFs have a limited solvent strength for many polymers of interest, which restricts its application. There is another disadvantage in that it is very difficult to control the coating or encapsulation because the nucleation and precipitation of coating materials take place very fast (less than $10^{-5} \mathrm{~s}$ ) during RESS [28].

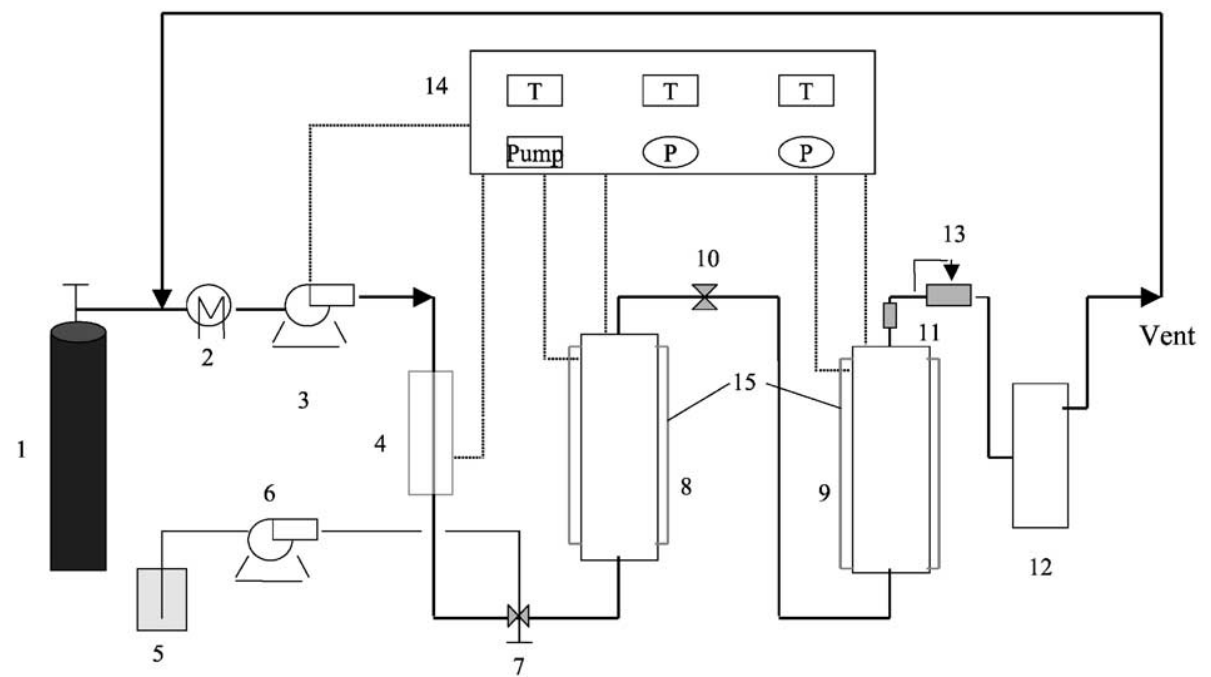

Fig. 1. Diagram of coating process using supercritical $\mathrm{CO}_{2}$. (1) $\mathrm{CO}_{2}$ cylinder. (2) Cooling. (3) Pump. (4) Preheating. (5) Cosolvent. (6) HPLC pump. (7) Threeway valve. (8) Extraction unit. (9) Precipitator. (10) On-off valve. (11) Filter. (12) Separator. (13) Back pressure regulator. (14) Control panel. (15) Heating mantle. 
(a)

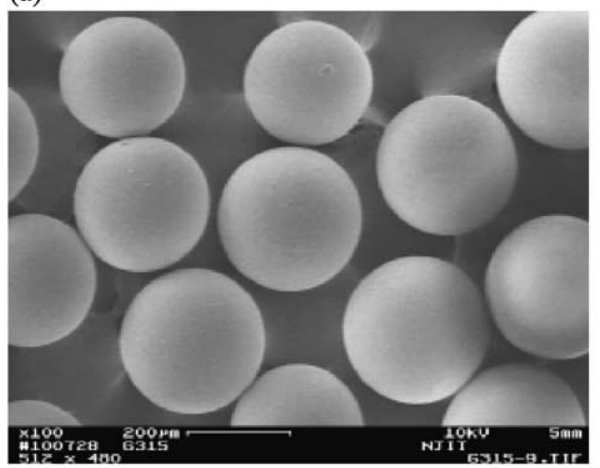

(c)

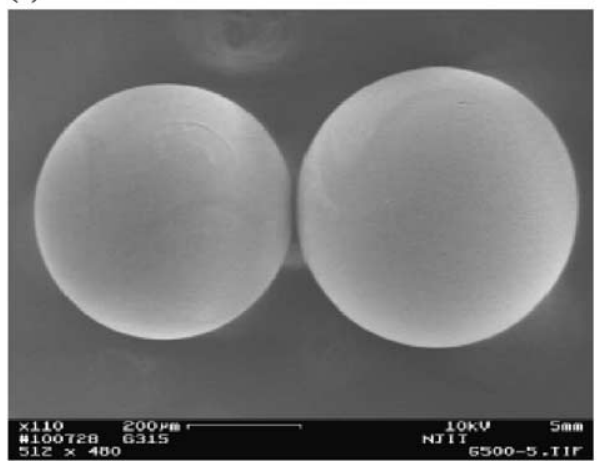

(b)

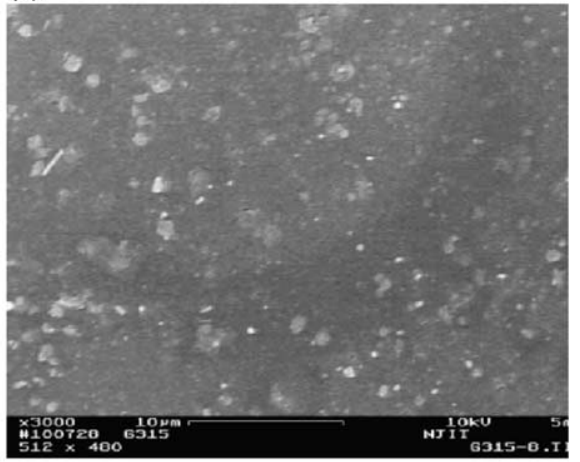

(d)

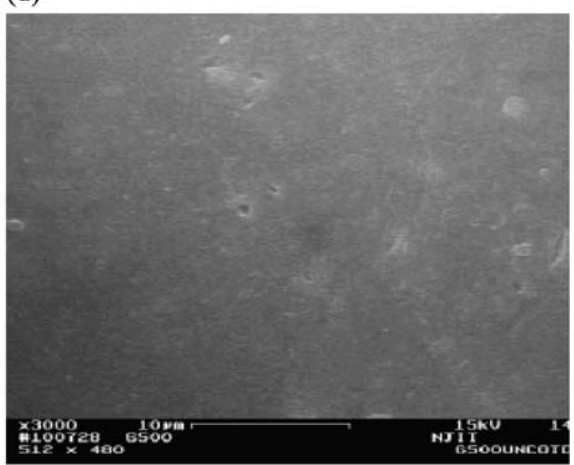

Fig. 2. SEM photographs of unprocessed glass beads at different magnifications: (a) $315 \mu \mathrm{m} \times 100$; (b) $315 \mu \mathrm{m} \times 3000$; (c) $500 \mu \mathrm{m} \times 110$; (d) 500 $\mu \mathrm{m} \times 3000$.

(a)

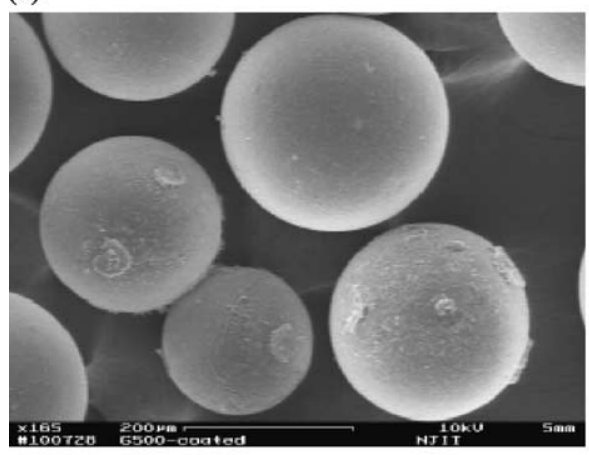

(c)

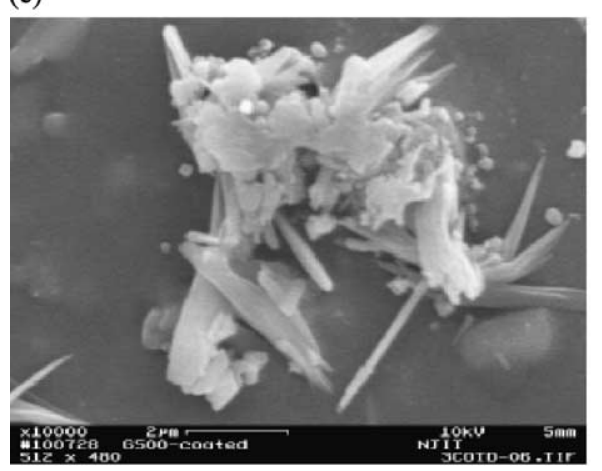

(b)

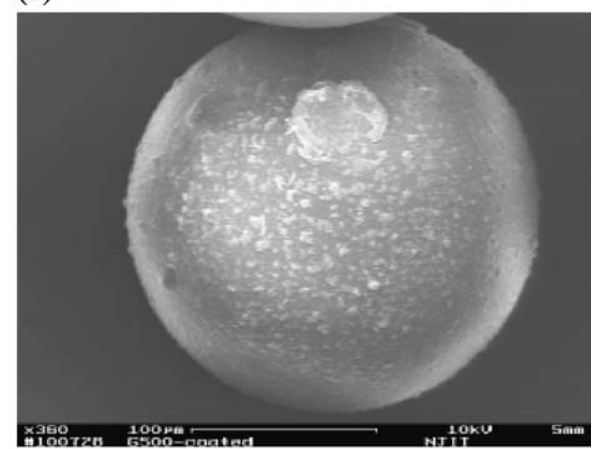

(d)

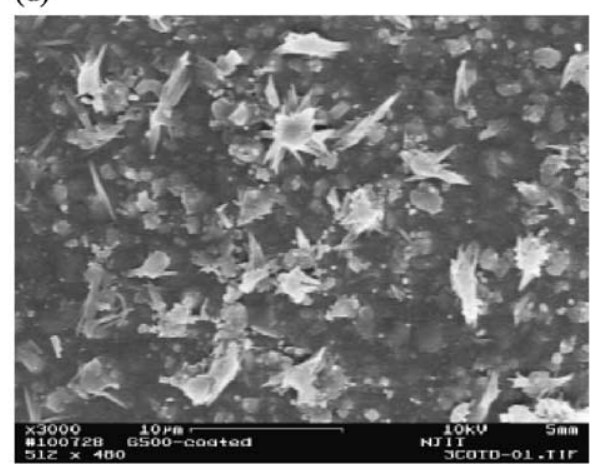

Fig. 3. SEM photographs of coated glass beads $(315 \mu \mathrm{m})$ at different magnifications: (a) $\times 100$; (b) $\times 360$; (c) $\times 10,000$; (d) $\times 3000$. 
Bertucco and Vaccaro [29] used the GAS technique for particle encapsulation. In their research, particles of $\mathrm{KCl}$ were suspended in a solution of polymer (hydroxypropyl methylcellulose phthalate, Eudragit E 100, ethylcellulose) in various organic solvents (toluene, acetone, 1,4-dioxane, ethylacetate). Compressed $\mathrm{CO}_{2}$ was introduced into the vessel as an antisolvent. Preliminary results showed that partial polymer encapsulation was achieved.

A recent study of Young et al. [30] investigated the encapsulation of lysozyme with biodegradable polymer by precipitation with a vapor-over-liquid antisolvent, which is a modified precipitation with a compressed antisolvent (PCA) process. A slurry of $1-10-\mu \mathrm{m}$ lysozyme particles suspended in a polymer solution was sprayed into $\mathrm{CO}_{2}$ vapor over $\mathrm{CO}_{2}$ liquid (below supercritical conditions) through a nozzle. By delayed precipitation, particles were allowed to grow large enough to encapsulate lysozyme. The polymer particles entraining lysozyme vitrified after falling into the $\mathrm{CO}_{2}$ liquid phase and agglomeration was avoided.

There are also some studies [31,32] dealing with composite microsphere production by the SAS process. A homogeneous solution of interesting solutes and polymer,

(a)

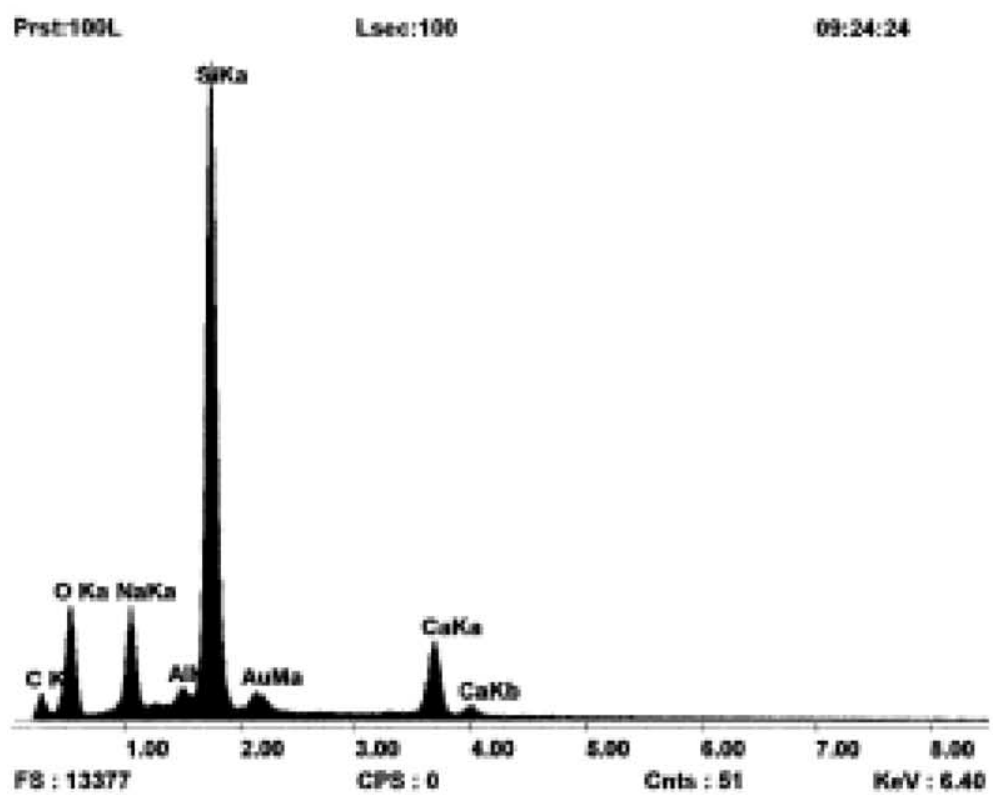

(b)

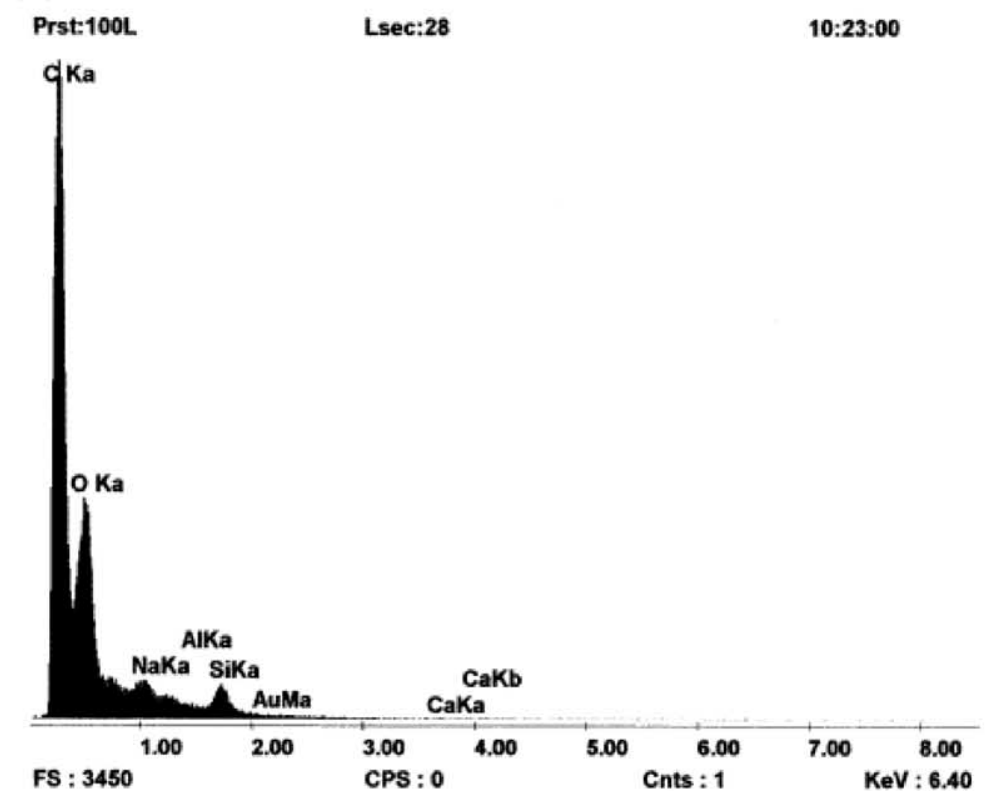

Fig. 4. EDS of unprocessed (a) and coated (b) glass beads (315 $\mu \mathrm{m})$. 
which was prepared by the hydrophobic ion-pairing (HIP) method [31] or by mixed solvents [32], was sprayed into supercritical $\mathrm{CO}_{2}$ antisolvent. Coprecipitation of the solutes and polymer was expected and composite microspheres or microcapsules were formed. However, coprecipitation of two different solutes is difficult to achieve even when the precipitation pressures of the solutes are close to each other [29]. In addition, exposure of proteins to solvents required for SAS leads to denaturing of the proteins probably due to a change in conformation [33], although some denaturation is partially reversible $[33,34]$.

In this preliminary work, a modified RESS technique was used to explore the coating of host particles with polymer using supercritical $\mathrm{CO}_{2}$ and a small amount of cosolvent to increase the solubility of the polymer in supercritical $\mathrm{CO}_{2}$. The modified RESS technique involves extracting the polymer with supercritical $\mathrm{CO}_{2}$, with or without a cosolvent in an extraction vessel, and then precipitating the polymer onto the surface of host particles in a second precipitation vessel by adjusting the pressure and temperature inside the precipitator to lower its solubility in supercritical $\mathrm{CO}_{2}$.

Spherical glass beads (315 and $500 \mu \mathrm{m})$ were chosen as host particles for the reason that glass beads are spherical and nearly monodisperse and, therefore, the coatings obtained could be more easily characterized. Two different polymers were tested in the coating experiments. The coating of much finer powders with biodegradable polymers using supercritical processing for drug delivery purposes will be reported in a future paper.

\section{Materials, methods and characterization}

\subsection{Materials}

In this study, $\mathrm{CO}_{2}$ was obtained from Air Liquide (France); purity is $99.995 \%$. Two polymers, polyvinyl chloride-co-vinyl acetate (PVCVA) (Aldrich, USA) and hydroxypropyl cellulose (HPC), which is soluble in water, were used. The properties of the two polymers are listed in Table 1. Unfortunately, no solubility data for these two polymers in supercritical $\mathrm{CO}_{2}$ could be found in the literature, but it was assumed that their solubility was extremely limited. Therefore, acetone $(99.5 \%$, Fisher, France) was chosen as a cosolvent since it is widely used to increase polymer solubility by improving dispersion, inducing dipolar interactions and by increasing the solvent density [35]. Monodisperse spherical glass beads with diameters of 315 and $500 \mu \mathrm{m}$ (Potters-Ballotini, France) were chosen as host particles.

\subsection{Methods}

The coating experiments using supercritical $\mathrm{CO}_{2}$ were performed on a pilot-scale apparatus (Separex, France), which is shown schematically in Fig. 1. Liquid $\mathrm{CO}_{2}$ was delivered by a Lewa metering pump from a $\mathrm{CO}_{2}$ tank and was cooled down to around $0{ }^{\circ} \mathrm{C}$ before entering the pump head. Cosolvent was introduced using a Gilson piston pump. The polymer substrate was packed in a stainless steel vessel having a volume of 1.51 , which served as the extraction unit. Another vessel with the same capacity was used as a precipitator and held the glass beads. The temperature of each of the two vessels was maintained relatively constant by an electrical heating mantle. $\mathrm{CO}_{2}$, with or without cosolvent, was charged from the bottom of the extraction unit to extract the packed polymer. The supercritical solution of polymer was then introduced into the bottom of the precipitator. By adjusting the pressure and temperature inside the precipitator, the solute would precipitate and deposit on the surface of the host particles. After a certain amount of running time, the cosolvent supply was stopped and pure $\mathrm{CO}_{2}$ was continued to flush the precipitator for some time under the same conditions to remove the cosolvent. Then the $\mathrm{CO}_{2}$ supply was shut off and the precipitator was slowly depressurized. The coated glass beads were recovered from the precipitator for characterization and further analysis. The operating parameters are given in Table 2. (a)

SE, 255

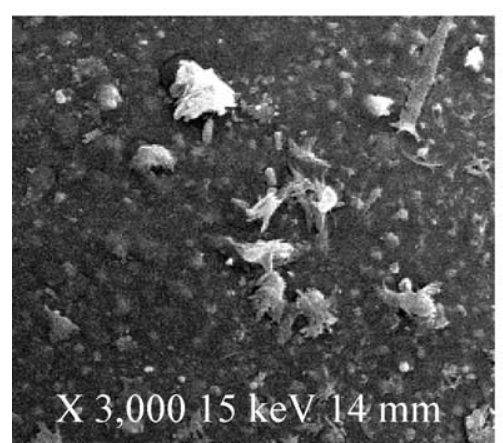

(b)

Cka,

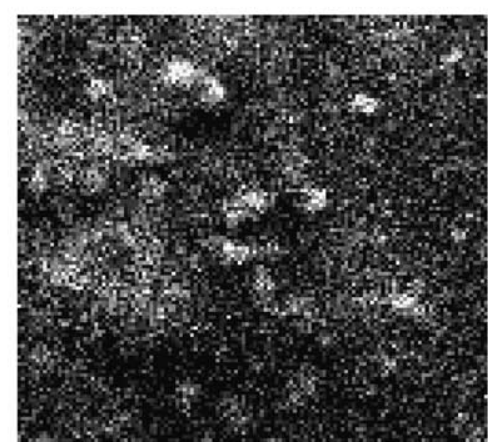

(c)

$\mathrm{SiKa}$,

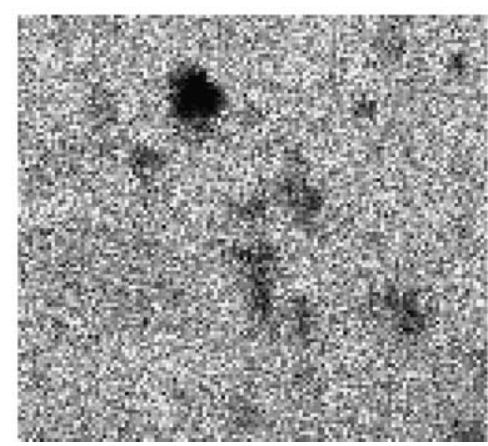

Fig. 5. EDS mapping of coated glass beads (315 $\mu \mathrm{m})$ : (a) SEM image; (b) carbon mapping; (c) silicon mapping. 
(a)

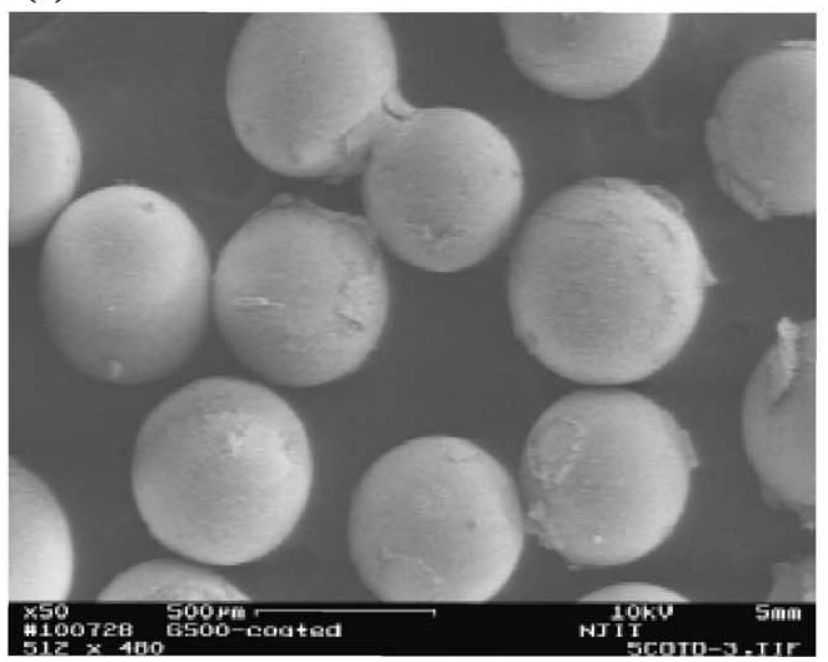

(c)

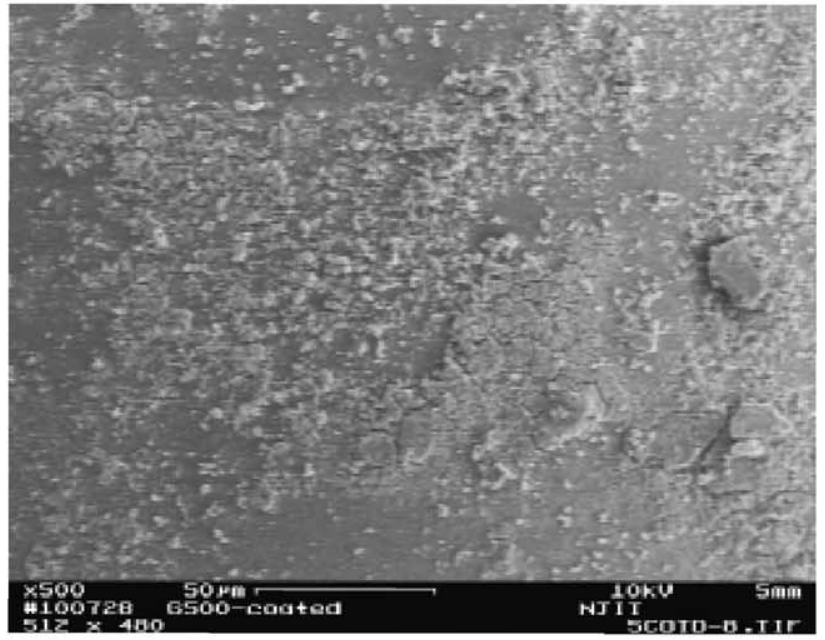

(e)

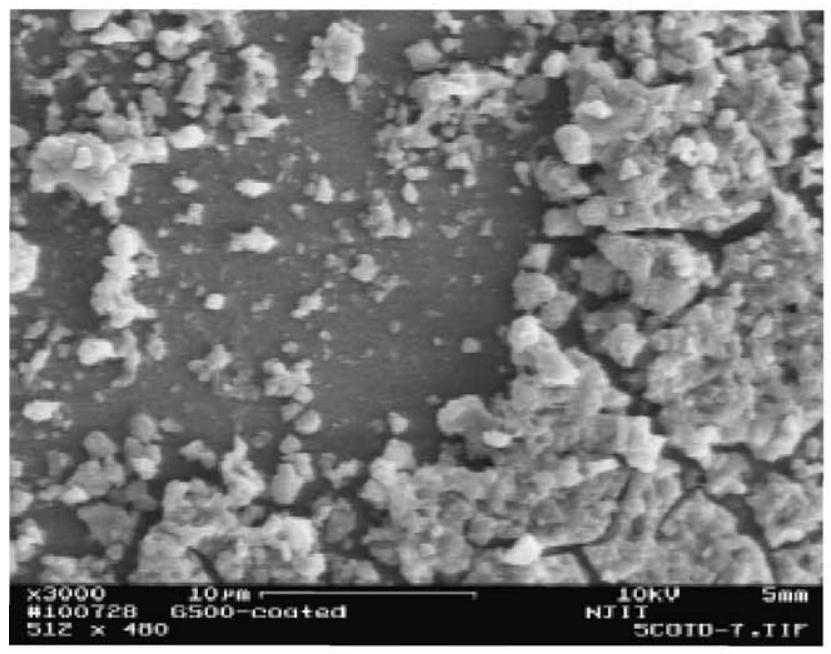

(b)

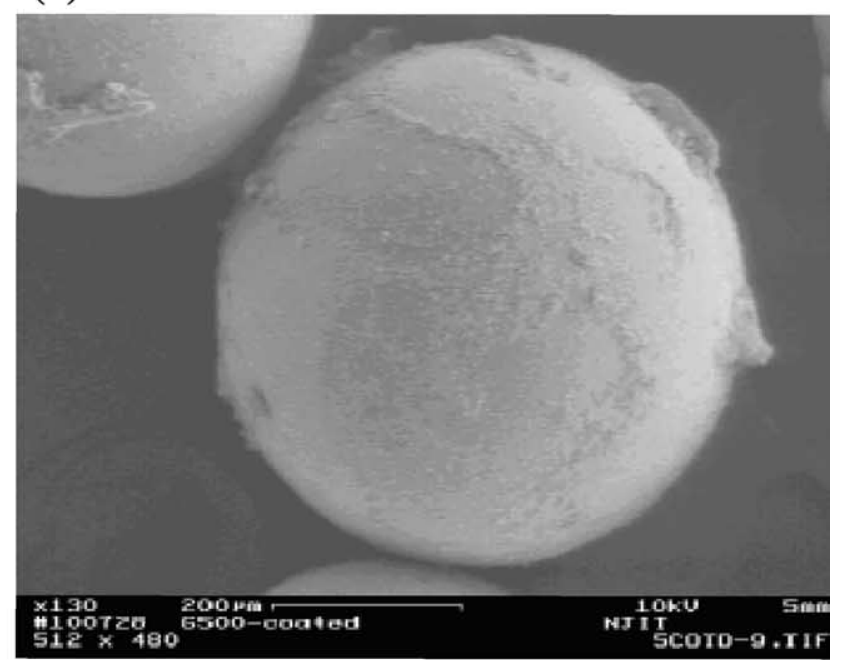

(d)

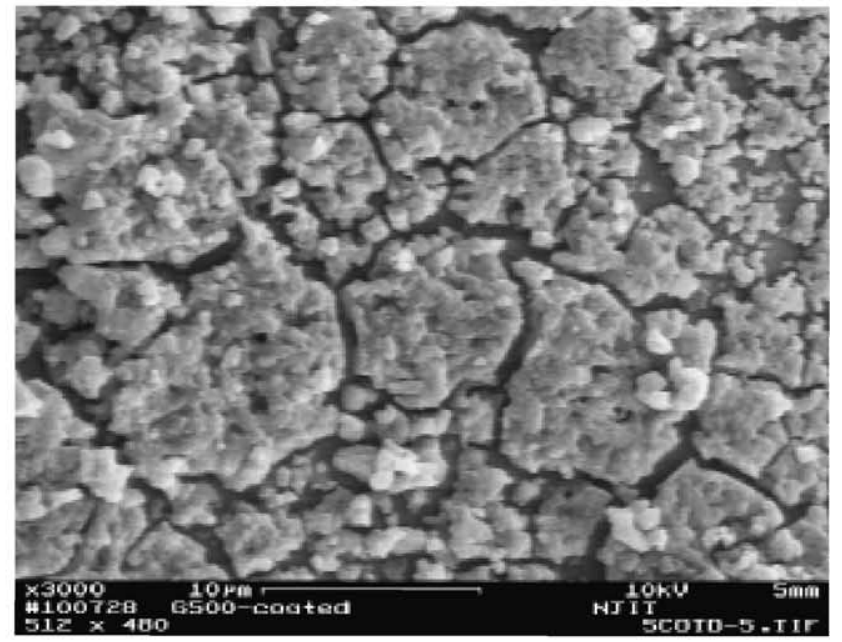

(f)

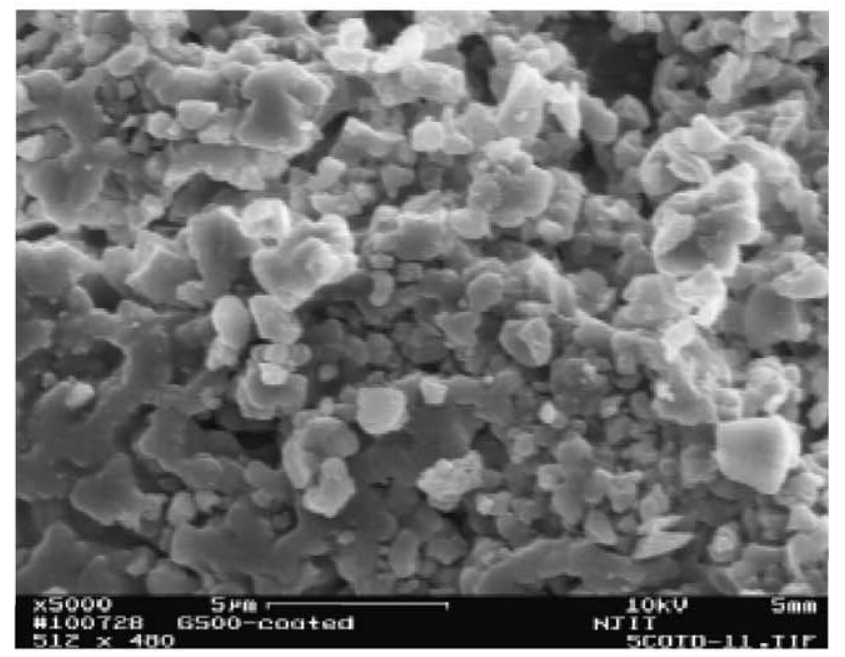

Fig. 6. SEM photographs of coated glass beads $(500 \mu \mathrm{m})$ at different magnifications: (a) $\times 50$; (b) $\times 130$; (c) $\times 500$; (d) $\times 3000$; (e) $\times 3000$; (f) $\times 5000$. 


\subsection{Characterization}

In this study, a Leo 982 scanning electron microscope (SEM) was employed for the morphological analysis. Samples were sputtered by palladium (SPI Sputter). Energy dispersive X-ray spectrometry (EDS) was used to analyze the elements on the surface of the uncoated and coated glass beads. The energy dispersive X-ray mapping technique was used to image the spatial distribution of elements on the surface of the particles. A TGA7 thermogravimetric analyzer (TGA) was used to estimate the thickness of the coating (see Appendix A).

\section{Results and discussion}

\subsection{Coating with PVCVA}

In the experiment of coating glass beads $(315 \mu \mathrm{m})$ with PVCVA, the temperature of the extraction unit was maintained around $80{ }^{\circ} \mathrm{C}$ and the pressure up to 127 bars. Acetone as cosolvent was delivered at a rate of $2 \mathrm{ml} / \mathrm{min}$, to improve the solubility. The temperature of the precipitator was kept at $30{ }^{\circ} \mathrm{C}$ and the pressure of the precipitator was kept around 118 bars by the back pressure regulator. These conditions of temperature and pressure were chosen because it was assumed that any inherent solubility of the polymer in supercritical $\mathrm{CO}_{2}$ would decrease rapidly as the pressure and temperature approaches the critical point [36] and because they allow for a single-phase mixture after depressurization. Furthermore, O'Neill et al. [37] state that: "Polymers in general have very limited solubility in supercritical fluid (SF) $\mathrm{CO}_{2}$ at temperatures below $80{ }^{\circ} \mathrm{C}$, although solubilities can increase significantly at higher temperature." Thus, in spite of a marked increase in the density of supercritical $\mathrm{CO}_{2}$ (e.g., using the Peng-Robinson [38] equation of state, the density of pure $\mathrm{CO}_{2}$ is 0.321 at 127 bars and $80{ }^{\circ} \mathrm{C}$ and 0.770 at 118 bars and $30{ }^{\circ} \mathrm{C}$ ), polymers appear to be much less soluble at lower temperatures. This was verified by our experiments since we could collect polymer-coated glass beads by decreasing both the pressure and the temperature in the precipitation vessel.

After 25 min of operation and 10 min of flushing (see Table 2, PVCVA-1), the sample was collected from the precipitator for characterization. Fig. 2 shows SEM photographs at two different magnifications of both the unprocessed 315 and 500 $\mu \mathrm{m}$ glass beads, which were used as host particles. As can be seen in the figure, the unprocessed glass beads are monodisperse and are quite smooth and clean on the surface with some small defects. SEM photographs of the $315 \mu \mathrm{m}$ glass beads coated with PVCVA are shown in Fig. 3. Compared with Fig. 2, Fig. 3a and b clearly shows that the glass beads are coated with polymer, although the coating is not uniform, nor is it continuously distributed over the surface.

In this coating process, due to changes in pressure and temperature (pressure from 127 to 118 bars and temperature from 80 to $30{ }^{\circ} \mathrm{C}$ ), the solvent strength of the supercritical $\mathrm{CO}_{2}$ is strongly affected, leading to a decreasing solubility of the polymer in the supercritical fluid. As the pressure and temperature decrease, the polymer nucleates. The nuclei grow into crystalline aggregates and deposit on the surface of the glass beads. This mechanism of polymer precipitation and coating is supported by Fig. 3c, which shows a crystalline aggregate on the glass bead surface. Many discrete polymer aggregates are seen attached on the surface in Fig. $3 \mathrm{~d}$.

Surface elemental analysis, using the EDS technique, can indicate what elements are on the surface of a particle. Fig. 4a shows the EDS pattern of unprocessed glass $(315 \mu \mathrm{m})$ beads. Obviously, the dominant element is silicon on the surface because it is a primary component of glass. Oxygen and sodium are secondary elements contained in the glass beads. The carbon peak, however, is very small compared with that of silicon and is probably due to some impurities or contaminants attached on the surface. The EDS pattern of

\section{(a)}

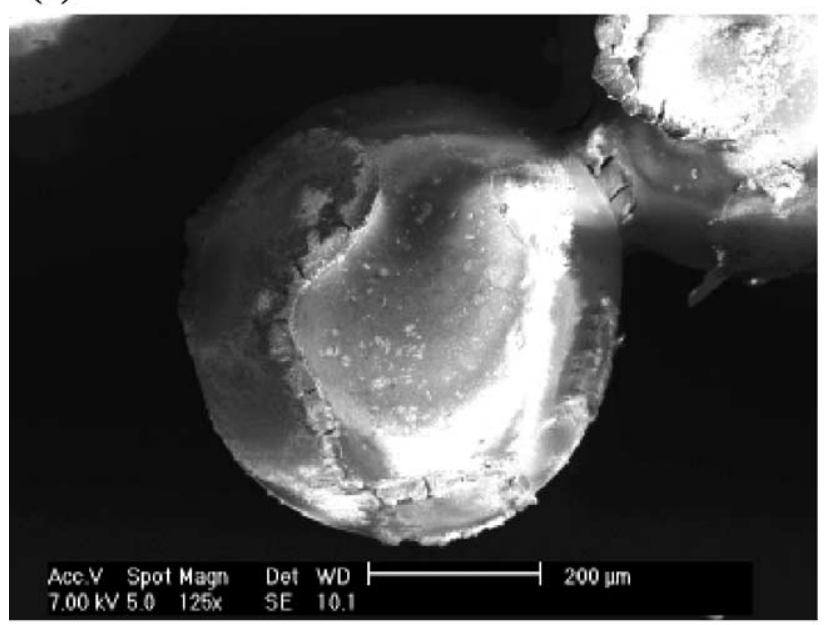

(b)

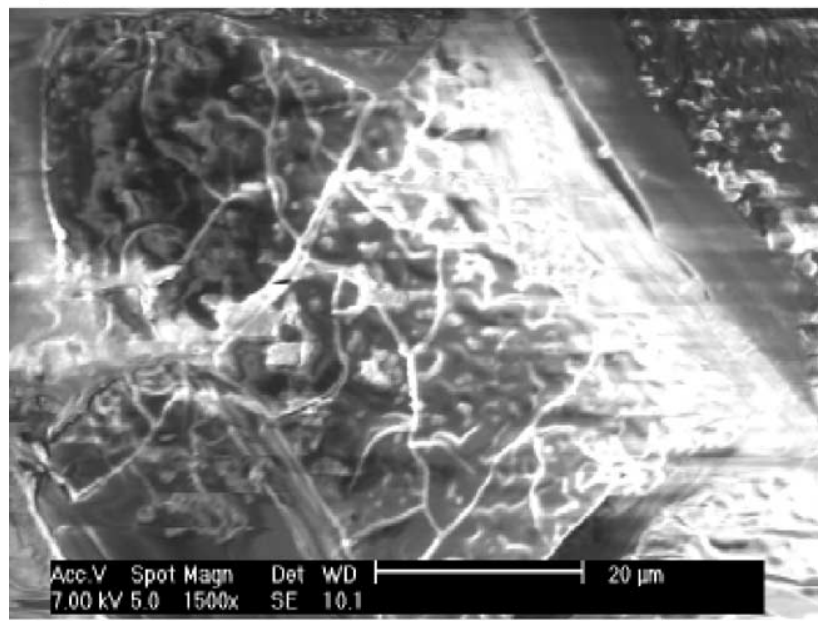

Fig. 7. SEM photograph of glass bead agglomerate (a) and polymer bridge (b). 
the processed glass beads is shown in Fig. 4b. Here the carbon signal is very strong, and it is the primary element on the surface, with oxygen seen as the second dominant element on the surface of the processed glass beads. This is consistent with the polymer's composition. Moreover, the silicon signal is very weak because it is blocked by the polymer coating layer. From Fig. 4, it is evident that the processed glass beads are coated with polymer, confirming the observation in Fig. 3.

The processed glass beads were also examined by using the EDS mapping technique, which reflects the spatial distribution of different elements. Fig. 5a shows the SEM image of the surface of a coated glass bead. Fig. 5b is the EDS mapping pattern for the element carbon on the same glass bead. The white dots represent the signals of carbon on the surface of the glass bead; it is clear that the glass bead is not uniformly covered with PVCVA polymer. Similarly, an EDS mapping of silicon can be found in Fig. 5c. A comparison of Fig. $5 \mathrm{~b}$ and $\mathrm{c}$ shows that the carbon signal is much weaker than that of the silicon signal over most of the surface because the polymer coating is very discrete. Also, we can see that where the carbon signal is strong, the (a)

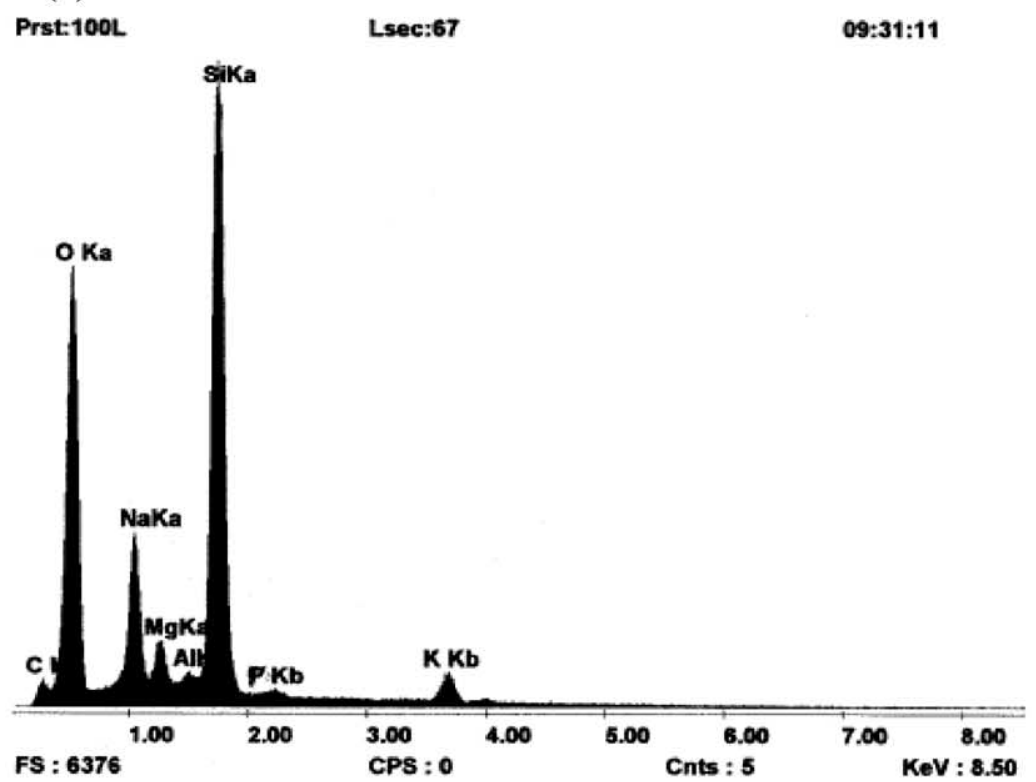

(b)

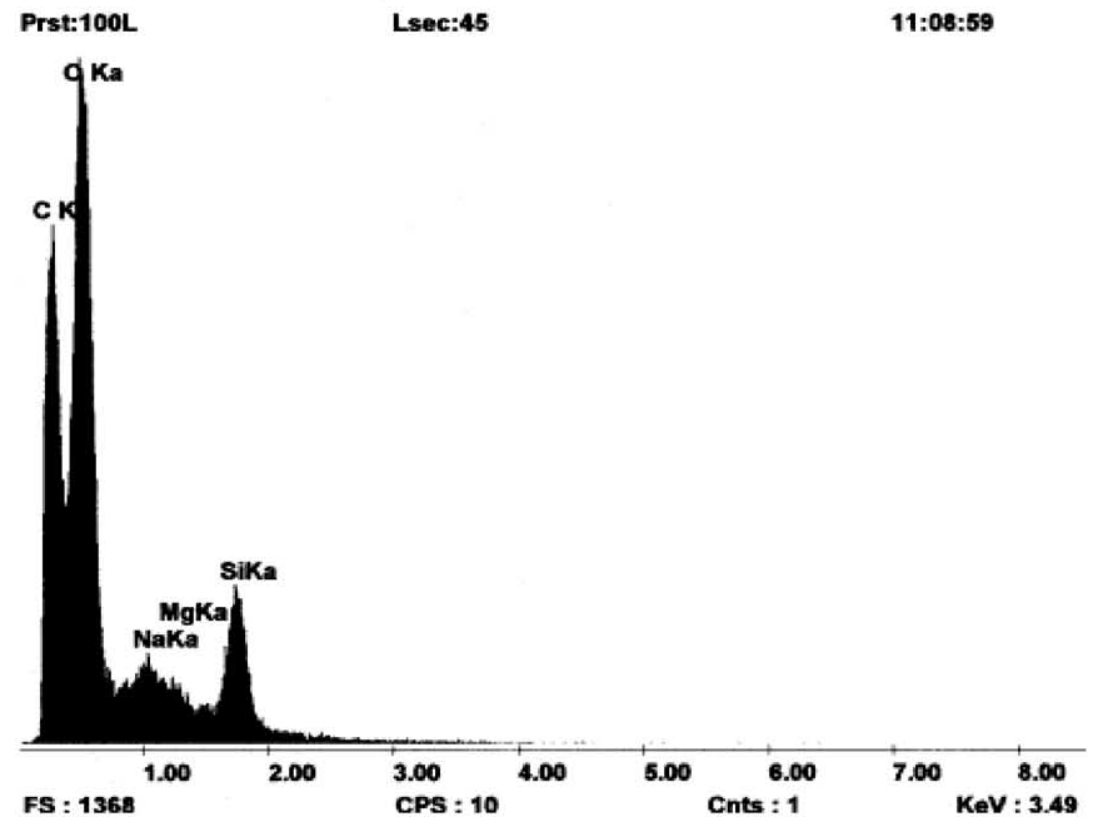

Fig. 8. EDS of unprocessed (a) and coated (b) glass beads (500 $\mu \mathrm{m})$. 


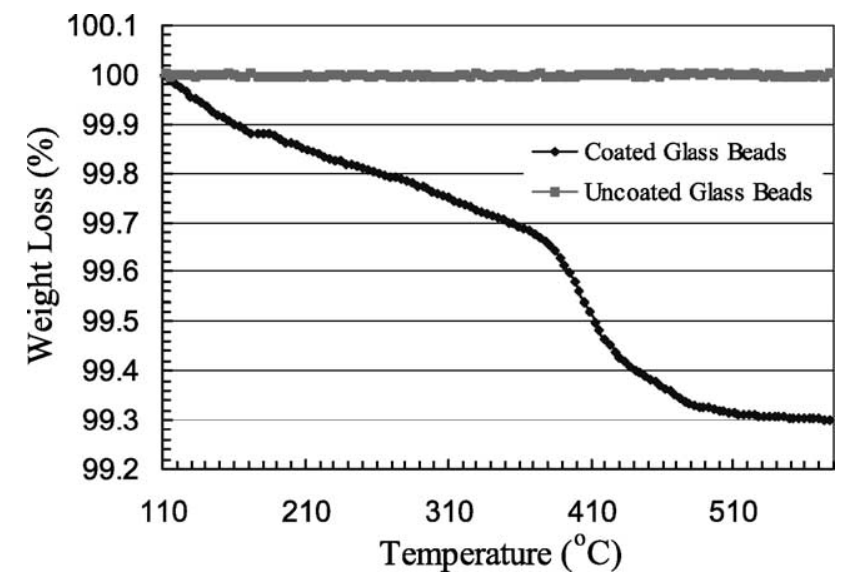

Fig. 9. TGA pattern of uncoated $(500 \mu \mathrm{m})$ and coated $(500 \mu \mathrm{m})$ glass beads with PVCVA.

silicon signal is weak. The polymer on the surface blocks the X-ray so that there is a very weak silicon signal in the area where the polymer deposits. The result of EDS map-

(a)

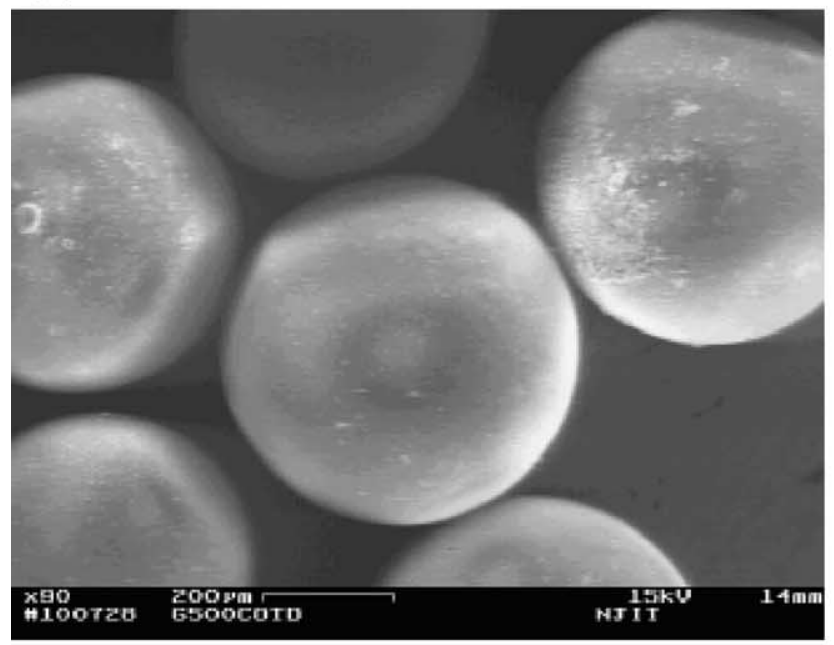

(c)

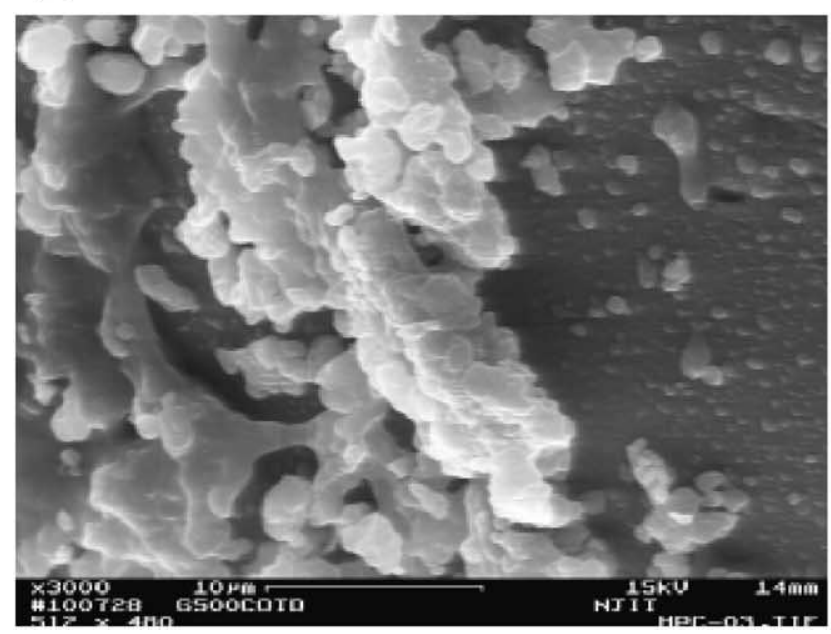

ping strongly supports the conclusion that the white material seen in Fig. 5a is polymer precipitated on the surface of the glass beads.

Another set of coating experiments was carried out by using $500-\mu \mathrm{m}$ glass beads as the host particles. It should be noted that no cosolvent was added in these experiments. They were operated under the conditions that the extraction temperature and pressure were maintained at $84{ }^{\circ} \mathrm{C}$ and 130 bars and the precipitation temperature and pressure were maintained at $48{ }^{\circ} \mathrm{C}$ and 117 bars. The experiment was run for $12 \mathrm{~min}$ (see Table 2, PVCVA-2) with no $\mathrm{CO}_{2}$ flushing necessary since no cosolvent was used.

SEM photographs of the coated glass beads at different magnifications are shown in Fig. 6. When compared to the unprocessed $500-\mu \mathrm{m}$ glass beads shown in Fig. 2, it is observed that the morphology and surface texture of the coated glass beads are different from those of the uncoated glass beads. Fig. $6 a$ and $b$ clearly shows that the glass beads are coated with polymer. Fig. 6c shows that parts of the surface are heavily covered by polymer, while a loose and

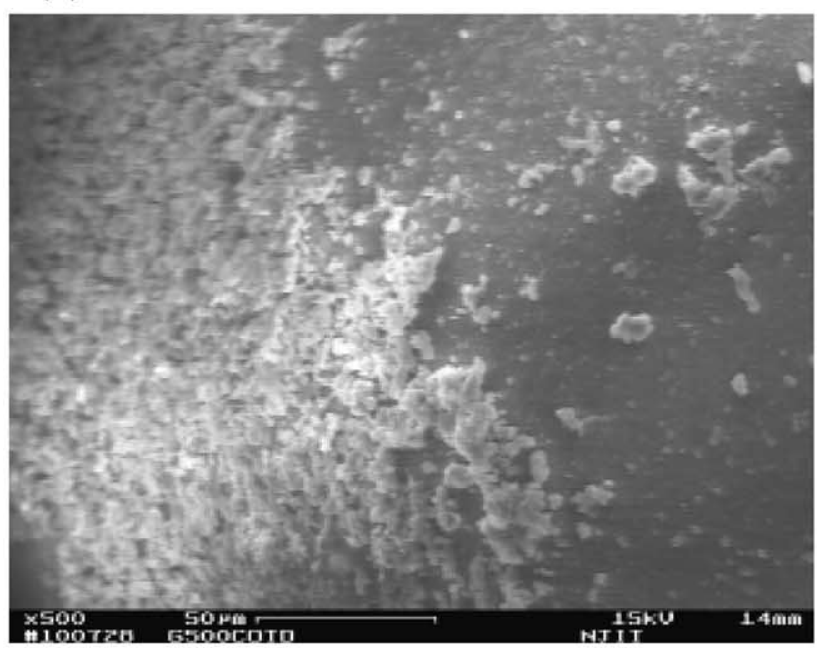

(d)

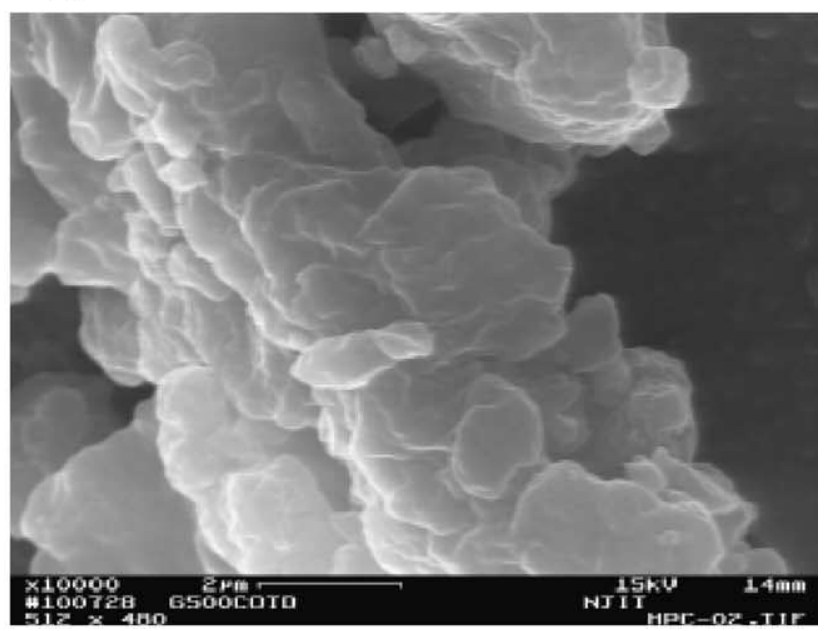

Fig. 10. SEM photographs of coated glass beads $(500 \mu \mathrm{m})$ with HPC at different magnifications: (a) $\times 90$; (b) $\times 500$; (c) $\times 3000$; (d) $\times 10,000$. 
discrete coating is developed on other parts of surface (Fig. $6 \mathrm{~d}$ and e). The highest magnification (Fig. 6f) shows that fine polymer particles (around $2 \mu \mathrm{m}$ ) aggregate on the surface. The $2-\mu \mathrm{m}$ polymer particles were produced due to the change in the temperature and pressure of $\mathrm{CO}_{2}$, which lowers the solubility of polymer in the supercritical $\mathrm{CO}_{2}$ $[3,37]$.

In our coating experiments, the glass beads simply sat on the bottom of the precipitator vessel and no stirrer was used. Thus, there were many dead areas and the precipitating polymer could not deposit on all of the surfaces of the glass beads even though there was sufficient precipitant available. Consequently, uneven coating is observed. However, fluidizing or stirring the host particles to avoid dead areas so that entire glass bead surface can be exposed to the polymer precipitant may overcome this problem.

Fig. 7a shows two glass beads "glued" together by polymer. Due to the $\mathrm{CO}_{2}$ pressure and temperature variation, the polymer nucleates and grows, falling into the area between neighboring glass beads, forming a bridge as well as covering the surface. If enough polymer precipitant is present, it would spread between all of the neighboring glass beads during polymer vitrification. Fig. $7 \mathrm{~b}$ shows a high magnification of the polymer bridge between two glued glass beads.

Fig. 8a shows the EDS pattern of the unprocessed 500$\mu \mathrm{m}$ glass beads. Again, silicon appears as one of the main component elements on the surface, and the carbon intensity is negligible compared with that of silicon, indicating that carbon shows up on the surface only as a contaminant. For the coated glass beads (Fig. 8b), carbon appears as one of the two dominant elements and silicon has a much smaller peak. These results are consistent with what was observed in Fig. 4 when the $315-\mu \mathrm{m}$ glass beads were coated.

It is interesting to observe that the coating of the $315-\mu \mathrm{m}$ glass beads appears very different from that of 500- $\mu \mathrm{m}$ glass beads even though the same polymer PVCVA was employed in the experiments. The polymer coating on the surface of the 315- $\mu \mathrm{m}$ glass beads (Fig. 3) appears much more crystalline than the polymer coating on the surface of the 500$\mu \mathrm{m}$ glass beads (Fig. 6). These results are probably due to the use of acetone as a cosolvent in the coating of $315-\mu \mathrm{m}$ glass beads. Acetone is a good solvent for PVCVA and, thus, the solubility of PVCVA in the mixture of supercritical $\mathrm{CO}_{2}$ and acetone will increase. The mobility of the polymer chains will also increase. Therefore, the polymer chains can rearrange into a crystalline state during the precipitation [39]. When coating the 500- $\mu \mathrm{m}$ glass beads without acetone as cosolvent, by adjusting the temperature and pressure in the precipitation vessel, the polymer nuclei that are formed will be less inclined to rearrange into a crystalline state. Therefore, the polymer coating on the surface of the $500-\mu \mathrm{m}$ glass beads is observed to be amorphous rather than crystalline.

In order to measure the average thickness of the coating, a thermogravimetric analyzer (TGA) was used to remove the polymer from the surface of the glass beads. The mass of polymer can be determined by the weight loss during the heating process. The temperature of the sample was raised to $580{ }^{\circ} \mathrm{C}$ at a heating rate of $30{ }^{\circ} \mathrm{C} / \mathrm{min}$ in air. Fig. 9 shows the TGA patterns of both the uncoated glass beads and the glass beads coated with PVCVA polymer. The figure shows that the weight of the uncoated glass bead sample stays constant during the experiment. For the coated glass beads, the weight loss is about $0.7 \%$ when run under the same conditions as the uncoated glass beads. Therefore the TGA analysis results also support the conclusion that the glass beads are coated with the polymer. The average thickness of the coating can even be evaluated by using the formula given in Appendix A and was found to be about $0.8 \mu \mathrm{m}$.

\subsection{Coating with $H P C$}

Hydroxypropyl cellulose (HPC) is a natural cellulose and is often used in pharmaceutical applications. However, it is hard to handle due to the lack of an appropriate solvent. Usually, ethanol is used, but it will form a gel or highly

(a)

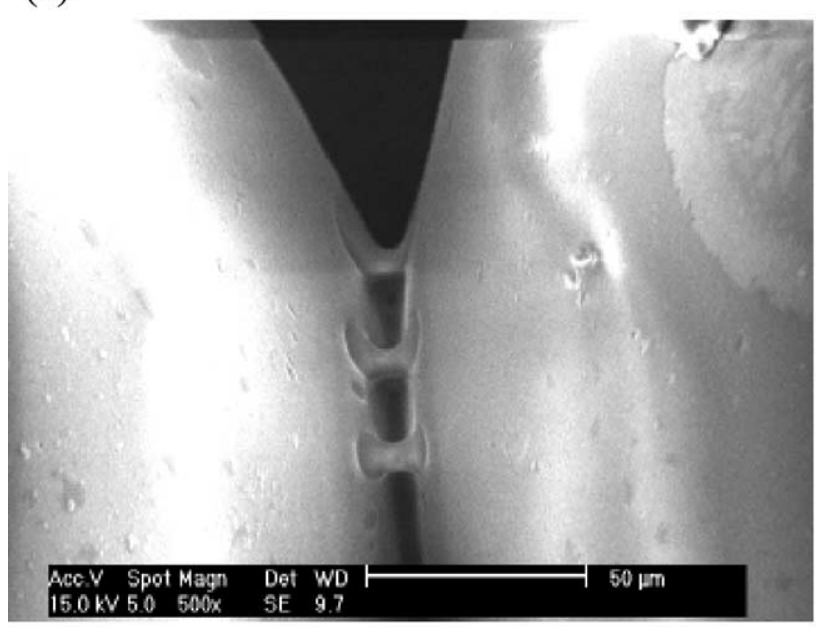

(b)

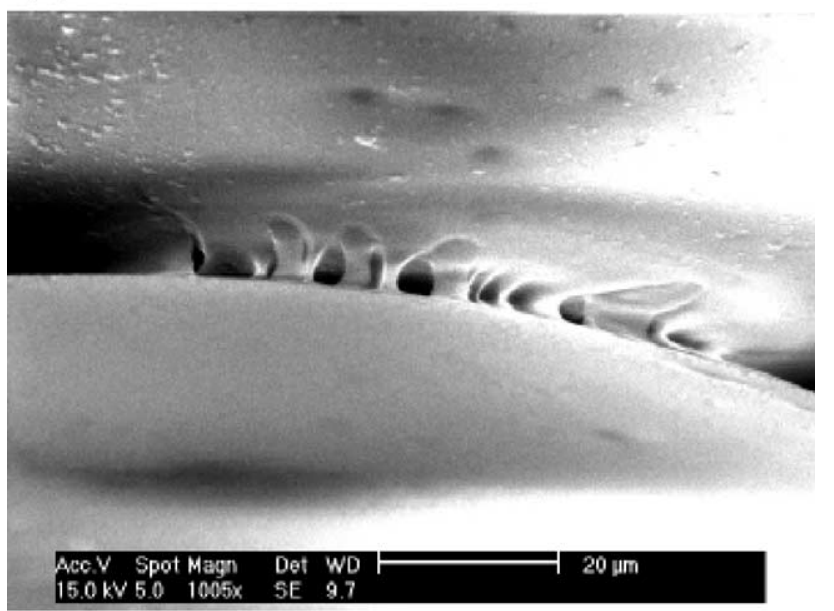

Fig. 11. SEM photographs of glass bead agglomerate. 


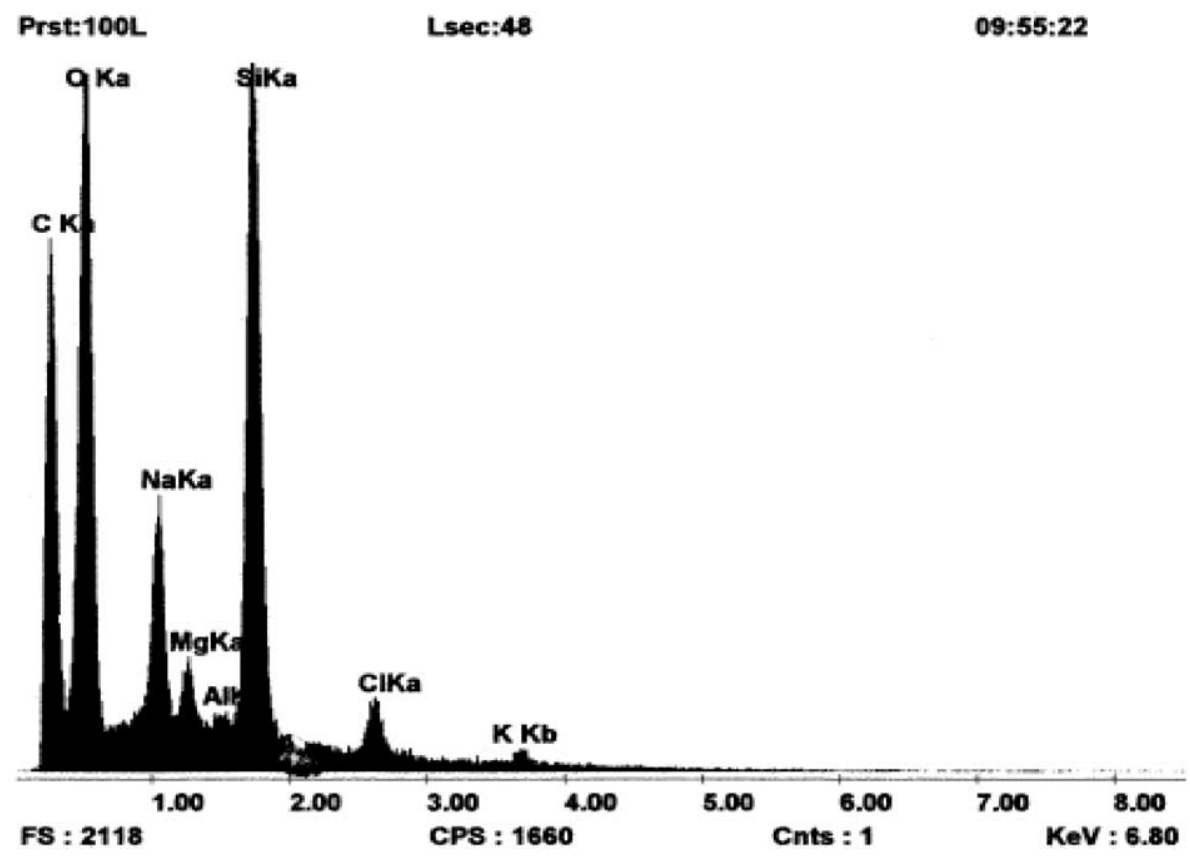

Fig. 12. EDS pattern of coated glass beads $(500 \mu \mathrm{m})$ with HPC.

viscous liquid when small amounts of ethanol are added. Moreover, other organic halide solvents are strictly prohibited in food and pharmaceutical handling because residual solvents could have ill effects on health.

As part of this research of particle coating with polymer, HPC was used for the coating of glass beads using supercritical $\mathrm{CO}_{2}$. Although acetone is not considered to be a good solvent for HPC, it can improve the solvating power of supercritical $\mathrm{CO}_{2}$ and was used as a cosolvent [40].

For the coating of $500-\mu \mathrm{m}$ glass beads with HPC, the extraction pressure and temperature were set at 106 bars and $80{ }^{\circ} \mathrm{C}$, respectively. The precipitator was kept at 80 bars and $30{ }^{\circ} \mathrm{C}$, very close to the critical point of $\mathrm{CO}_{2}$ where the solubility of polymer is much lower [36]. Acetone was delivered at $2 \mathrm{ml} / \mathrm{min}$. The experiment was run for $20 \mathrm{~min}$, followed by $10 \mathrm{~min}$ of flushing with $\mathrm{CO}_{2}$ (see Table 2, HPC).

Fig. 10 shows SEM pictures of $500-\mu \mathrm{m}$ glass beads processed with HPC. Compared with Fig. 2, it appears that while the glass beads are coated with HPC, the coating is less than that with PVCVA. Moreover, the coating is very discrete with large areas of the surface left uncoated. When examining the SEM pictures in Figs. 6 and 10, it is observed that a higher degree of covering occurred with PVCVA on the glass bead surface than with HPC. This might be due to a lower solubility of HPC as compared to PVCVA in SC $\mathrm{CO}_{2}$. In the coating experiments with $\mathrm{HPC}$, the first run was performed under the same conditions mentioned above except no cosolvent was added. Without the cosolvent, it was observed that no coating occurred on the surface of the glass beads. Since HPC is polar and a hydrophilic polymer, the solubility of HPC in supercritical $\mathrm{CO}_{2}$ is extremely low. Acetone acts as a cosolvent and improves the solvent strength of the supercritical $\mathrm{CO}_{2}$ considerably. The addition of organic solvents as a cosolvent to improve solvating power of supercritical fluid had been widely reported $[3,5,6,25]$.

Fig. 11a and b, at different magnifications, shows two glass beads stuck together with HPC. The polymer precipitant acts as binder between the glass beads and glues them together. This is again attributed to the fact that the glass beads were not stirred or fluidized in the precipitator.

The EDS pattern of the uncoated glass beads shows that silicon and oxygen are the two dominant elements on the surface, while carbon is negligible (Fig. 8). However, in Fig. 12, which shows the EDS pattern of the coated glass beads, the carbon intensity increases greatly and becomes one of three dominant elements on the surface, indicating that the surface of the glass beads was coated by HPC.

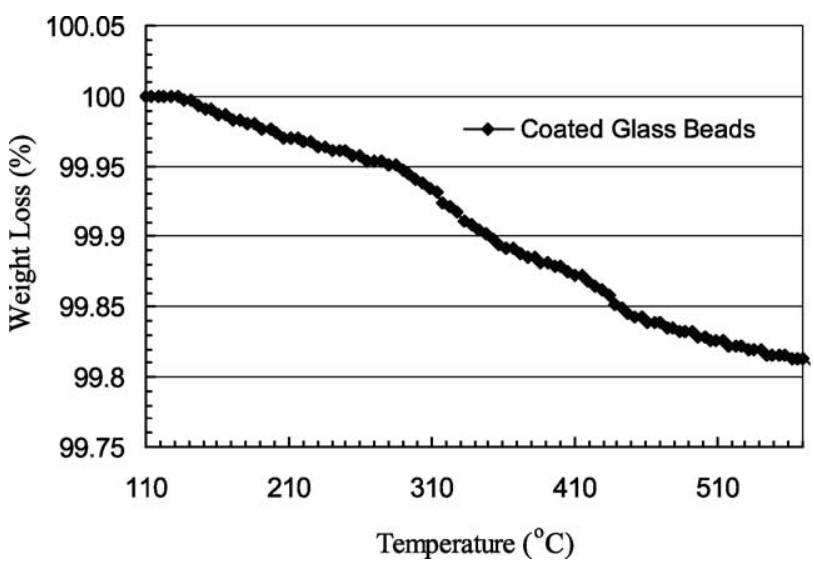

Fig. 13. TGA pattern of coated glass beads $(500 \mu \mathrm{m})$ with HPC. 
A TGA analysis of glass beads coated with HPC is shown in Fig. 13. Compared with uncoated glass beads (Fig. 9), the weight loss of about $0.17 \%$ confirms the conclusion that the glass beads are coated with polymer. Based on the formula given in Appendix A, the average coating thickness is about $0.24 \mu \mathrm{m}$, as compared to an average thickness of about $0.8 \mu \mathrm{m}$ for PVCVA. This supports the previous observation that more coating is obtained with PVCVA as compared to HPC due to a difference in solubility.

\section{Conclusions}

A modified RESS process was developed in this study for coating particles by using a solution of polymer in supercritical $\mathrm{CO}_{2}$. Our results show that the coating of glass beads with PVCVA and HPC was successfully achieved using this technique. Solubility plays a very important part in the coating process. The use of a cosolvent can improve the solubility of polymers and will also affect the degree of crystallinity of the polymer coating on the surface of glass beads. The extraction and precipitation technique takes advantage of the properties of a supercritical solution in that the polymer would nucleate, grow and deposit on the host particle surface due to changes in its solubility caused by adjusting the temperature and pressure. Fluidizing or stirring the host particles would probably result in a much more continuous and uniform coating than was obtained here. The process of particle coating using a supercritical solution is a promising alternative method for the coating of fine particles, with little or no organic solvents involved. It should be attractive for the pharmaceutical, food, cosmetic and other industries.

\section{Future work}

It was found that many factors have an effect on the coating process, such as temperature (extraction and precipitation), pressure (extraction and precipitation), flow rate and solubility of the polymer in supercritical $\mathrm{CO}_{2}$, with and without the presence of a cosolvent. Future work will be concerned with systematically varying the operating conditions, coating much smaller host particles in the $1-10-\mu \mathrm{m}$ size range and suspending the host particles by fluidization or stirring, thus, continuously exposing fresh surface to the supersaturated polymer solution.

\section{Acknowledgements}

The first author would like to thank Professor John Dodds for providing him the opportunity to do research at the Particle Technology Center in the Ecole des Mines d'Albi-Carmaux. He also thanks Dr. Rachel Calvet, Mrs. Maryse Collado and Ms. Sabine Leroux for their help with the experiments performed in Albi. The authors would also like to thank the National Science Foundation for financial support through Grant \#CTS-9985618, and the New Jersey Commission of Science and Technology for financial support through Award \#01-2042-007-24.

\section{Appendix A. TGA Analysis for estimation the thickness of the coating}

In TGA analysis of glass beads coated with polymer, the weight loss is considered to be the weight of the coating polymer since the host particle is inert. In these experiments, the temperature was increased from room temperature to $580{ }^{\circ} \mathrm{C}$ at a rate of $30{ }^{\circ} \mathrm{C} / \mathrm{min}$ using air. At this temperature, the polymer was completely burned off. The average thickness of the coating material is estimated using the formula below, assuming that the coating is continuous and the coating thickness is negligible compared with the diameter of the host particle.

$t=\frac{1}{6} \frac{m_{\mathrm{c}}}{m_{\mathrm{h}}} \frac{\rho_{\mathrm{h}}}{\rho_{\mathrm{c}}} D$

where $t$ : average thickness of coating, $m_{\mathrm{c}}$ : mass of coating material, $m_{\mathrm{h}}$ : mass of host particle, $\rho_{\mathrm{c}}$ : density of coating material, $\rho_{\mathrm{h}}$ : density of host particle, $D$ : diameter of host particle.

\section{References}

[1] R. Pfeffer, R.N. Dave, D. Wei, M. Ramlakhan, Synthesis of engineered particulates with tailored properties using dry particle coating, Powder Technol. 117 (2001) 40-67.

[2] V.J. Krukonis, Supercritical fluid nucleation of difficult-to-comminute solids, Annual Meeting AIChE, San Francisco, CA, November 1984, p. 140 .

[3] C.J. Chang, A.D. Randolph, Precipitation of microsized organic particles from supercritical fluids, AIChE J. 35 (11) (1989) 1876-1882.

[4] D.W. Matson, J.L. Fulton, R.C. Peterson, R.D. Smith, Rapid expansion of supercritical fluid solutions: solution formation of powders, thin films, and fibers, Ind. Eng. Chem. Res. 26 (11) (1987) 22982306.

[5] J.W. Tom, P.G. Debenedetti, Formation of bioerodible polymeric microspheres and microparticles by rapid expansion of supercritical solutions, Biotechnol. Prog. 7 (5) (1991) 403-411.

[6] J.W. Tom, P.G. Debenedetti, Precipitation of poly(L-lactic-acid) and composite poly(L-lactic-acid)-pyrene particles by rapid expansion of supercritical solutions, J. Supercrit. Fluids 7 (1994) 9-29.

[7] J.G. Cai, X.C. Liao, Z.Y. Zhou, Microparticle formation and crystallization rate of HMX using supercritical dioxide anti-solvent recrystallization, The 4th International Symposium on Supercritical Fluids, Sendai, Japan, Tohoku University Press, May 11-14, 1997, pp. $23-26$.

[8] S.D. Yeo, G.B. Lim, P.G. Debenedetti, H. Bernstein, Formation of microparticulate protein powders using a supercritical fluid anti-solvent, Biotechnol. Bioeng. 41 (1993) 341-346.

[9] A.K. Dillow, F. Dehghani, N. Foster, J. Hrkach, R.S. Langer, Production of polymeric support materials using supercritical fluid anti-solvent process, The 4th International Symposium on Supercritical 
Fluids, Sendai, Japan, Tohoku University Press, May 11-14, 1997, pp. 247-250.

[10] E. Reverchon, A.A. Barba, G. Della Porta, P. Ciamblli, D. Sannino, Production of catalyst precursors by supercritical anti-solvent precipitation (SAS), in: E. Reverchon (Ed.), The Fourth Italian Conference on Supercritical Fluids and their Application, Capri, CUES, Fisciano, Italy, September 7-10, 1997, pp. 385-391.

[11] E. Reverchon, G. Della Porta, S. Pace, A. Di Trolio, Supercritical antisolvent precipitation of submicronic particles of superconduct precursors, Ind. Eng. Chem. Res. 37 (3) (1998) 221-236.

[12] E. Reverchon, G. Della Porta, I. De Rosa, P. Subra, D. Letourneur, Supercritical antisolvent micronization of some biopolymers, J. Supercrit. Fluids 18 (2000) 239-245.

[13] P.M. Gallagher, M.P. Coffey, V.J. Krukonis, N. Klasutis, Gas antisolvent recrystallization: new process to recrystallize compounds insoluble in supercritical fluids, Supercritical Fluid Science and Technology, ACS Symposium Series, vol. 406, American Chemical Society, Washington, DC, 1989.

[14] P.M. Gallagher, M.P. Coffey, V.J. Krukonis, Gas anti-solvent recrystallization of RDX: formation of ultra-fine particles of a difficult-tocomminute explosive, J. Supecrit. Fluids 5 (1992) 130-142.

[15] G.B. Lim, S.Y. Lee, K.K. Koo, B.S. Park, H.S. Kim, Gas anti-solvent recrystallization of molecular explosives under subcritical to supercritical conditions, Proceedings of the 5th Meeting on Supercritical Fluids, Nice, ISASF, France, March 23-25, 1998, p. 271 (Tome1; ISBN 2-905-267-28-3).

[16] D.J. Dixon, K.P. Johnston, R.A. Bodmeier, Polymeric materials formed by precipitation with a compressed fluid anti-solvent, AIChE J. 39 (1) (1993) 127-139.

[17] M.A. Winter, D.Z. Frankel, P.G. Debenedetti, J. Carey, M. Devaney, T.M. Przybycien, Protein purification with vapor-phase carbon dioxide, Biotechnol. Bioeng. 62 (3) (1999) 247-258.

[18] E. Reverchon, G. Della Porta, D. Sannino, P. Ciamblli, Supercritical anti-solvent precipitation of nanoparticles of a zinc oxide precursor, Powder Technol. 102 (2) (1999) 129-136.

[19] W.J. Schmitt, M.C. Salada, G.G. Shook, S.M. Speaker, AIChE J. 41 (1995) 2476.

[20] Y.H. Chou, D.L. Tomasko, GAS crystallization of polymer-pharmaceutical composite particles, The 4th International Symposium on Supercritical Fluids, Sendai, Japan, Tohoku University Press, May $11-14,1997$, pp. $55-57$.

[21] J. Thies, B.W. Müller, Size controlled production of biodegradable microparticles with supercritical gases, Eur. J. Pharm. Biopharm. 45 (1998) 67-74.

[22] M. Hanna, P. York, B.Y. Shekunov, Control of the polymeric forms of a drug substance by solution enhanced dispersion by supercritical fluids (SEDS), Proceedings of the 5th Meeting on Supercritical Fluids, Nice, ISASF, France, March 23-25, 1998, pp. 325-330 (Tome1; ISBN 2-905-267-28-3).

[23] R. Sloan, M.E. Hollowood, G.O. Humpreys, W. Ashraf, P. York, Supercritical fluid processing: preparation of stable protein particles, Proceedings of the 5th Meeting on Supercritical Fluids, Nice, ISASF, France, March 23-25, 1998, pp. 301-306 (Tome1; ISBN 2-905-26728-3).

[24] J.H. Kim, T.E. Paxton, D.L. Tomasko, Microencapsulation of naprox- en using rapid expansion of supercritical solutions, Biotechnol. Prog. 12 (1996) 650-661.

[25] K. Mishima, K. Matsuyama, D. Tanabe, S. Yamauchi, T.J. Young, K.P. Johnston, Microencapsulation of proteins by rapid expansion of supercritical solution with a nonsolvent, AIChE J. 46 (4) (2000) $857-$ 865 .

[26] A. Tsutsumi, S. Nakamoto, T. Mineo, K. Yoshida, A novel fluidizedbed coating of fine particles by rapid expansion of supercritical fluid solutions, Powder Technol. 85 (1995) 275-278.

[27] T.J. Wang, A. Tsutsumi, H. Hasegawa, T. Mineo, Mechanism of particle coating granulation with RESS process in a fluidized bed, Powder Technol. 118 (2001) 229-235.

[28] D.W. Matson, R.C. Peterson, R.D. Smith, Production of fine powders by the rapid expansion of supercritical fluid solutions, Adv. Ceram. 21 (1987) $109-120$.

[29] A. Bertucco, F. Vaccaro, Drugs encapsulation using a compressed gas antisolvent technique, in: E. Reverchon (Ed.), The Fourth Italian Conference on Supercritical Fluids and their Application, Capri, CUES, Fisciano, Italy, September 7-10, 1997, pp. 327-334.

[30] T.J. Young, K.P. Johnston, K. Mishima, H. Tanaka, Encapsulation of lysozyme in a biodegradable polymer by precipitation with a vaporover-liquid antisolvent, J. Pharm. Sci. 88 (6) (1999) 640-650.

[31] R. Falk, T.W. Randolph, J.D. Meyer, R.M. Kelly, M.C. Manning, Controlled release of ionic compounds from poly (L-lactide) microspheres produced by precipitation with a compressed antisolvent, J. Controlled Release 44 (1997) 77-85.

[32] N. Elvassore, A. Bertucco, P. Caliceti, Production of protein-loaded polymeric microcapsules by compressed $\mathrm{CO}_{2}$ in a mixed solvent, Ind. Eng. Chem. Res. 40 (3) (2001) 795-800.

[33] S.D. Yeo, P.G. Debenedetti, S.Y. Patro, T.M. Przybycien, Secondary structure characterization of microparticulate insulin powders, J. Pharm. Sci. 83 (1994) 1651-1656.

[34] M.A. Winter, B.L. Knutson, P.G. Debenedetti, H.G. Sparks, T.M. Przybycien, C.L. Stevenson, S.J. Prestrelski, Precipitation of proteins in supercritical carbon dioxide, J. Pharm. Sci. 85 (1996) 586-594.

[35] C. Kirby, M. Mchugh, Phase behavior of polymers in supercritical fluid solvents, Chem. Rev. 99 (1999) 565-602.

[36] P.G. Debenedetti, S.K. Kumar, Infinite dilution fugacity coefficients and general behavior of dilute binary systems, AIChE J. 34 (4) (1988) $645-657$.

[37] M.L. O'Neill, Q. Cao, M. Fang, K.P. Johnston, S.P. Wilkinson, C. Smith, J.L. Kerschner, S.H. Jureller, Solubility of homopolymers and copolymers in carbon dioxide, Ind. Eng. Chem. Res. 37 (1998) 30673079.

[38] D.Y. Peng, D. Robinson, A new two-constant equation of state, Ind. Eng. Chem. Fundam. 15 (1976) 59-64.

[39] R.F. Falk, T.W. Randolph, Process variable implications for residual solvent removal and polymer morphology in the formation of gentamycin-loaded poly (L-lactide) microparticles, Pharm. Res. 15 (8) 1998, pp. 1233-1237.

[40] E. Kiran, H. Pöhler, Alternative solvents for cellulose derivatives: miscibility and density of cellulosic polymers in carbon dioxide + acetone and carbon dioxide + ethanol binary fluid mixtures, J. Supercrit. Fluids 13 (1998) 135-147. 